\title{
A Novel CD11c Monoclonal Antibody Effective in Formalin-Fixed Tissue for the Diagnosis of Hairy Cell Leukemia
}

\author{
Korinna Jöhrens $^{\mathrm{a}}$ Lisa C. Happerfield ${ }^{\mathrm{b}}$ John P. Brown ${ }^{\mathrm{b}}$ Wendy N. Erber ${ }^{\mathrm{c}}$ \\ Harald Stein $^{\mathrm{a}}$ Ioannis Anagnostopoulos ${ }^{\mathrm{a}}$ \\ anstitute of Pathology and Reference Center for Hematopathology, Charité, Medical University Berlin, Berlin, \\ Germany; Departments of ${ }^{b}$ Histopathology and ${ }^{\mathrm{C} H e m a t o l o g y, ~ A d d e n b r o o k e ' s ~ H o s p i t a l, ~ C a m b r i d g e, ~ U K ~}$
}

\section{Key Words}

Hairy cell leukemia - Bone marrow trephines • CD11c •

Formalin fixation

\begin{abstract}
Objective: The diagnosis of hairy cell leukemia ( $\mathrm{HCL})$ and its distinction from other B-cell lymphomas can be difficult in formalin-fixed tissue. This is because the histology is not always classical, and despite having a characteristic phenotype, there are few relevant monoclonal antibodies with sufficient sensitivity and specificity that can be applied to fixed material. In this study, we assessed the utility of a newly developed antibody against a formalin-resistant CD11c epitope (5D11) for the diagnosis and monitoring of HCL in formalin-fixed tissue. Methods: We performed immunohistochemical staining for CD11c expression in formalin-fixed and also decalcified tissue of 196 small B-cell lymphomas, including 104 cases of HCL showing extensive to minimal infiltrates. Results: The CD11c antibody was both sensitive and specific for $\mathrm{HCL}$, even in cases with minimal infiltration. Conclusion: We recommend that this CD11c antibody be added to a panel of antibodies for immunostaining of formalinfixed material, for differentiation of $\mathrm{HCL}$ from other small B-cell lymphomas, and for detection of residual disease following therapy.

Copyright $\odot 2008$ S. Karger AG, Basel
\end{abstract}

\section{Introduction}

Hairy cell leukemia (HCL) is a distinctive yet uncommon chronic B-cell lymphoproliferative disorder, predominantly involving the bone marrow and spleen. It primarily affects adult males [1]. A definitive distinction between HCL and other B-cell lymphomas associated with marked splenomegaly is important since potentially curative therapy is available for HCL. It responds to deoxycoformycin and 2-chlorodeoxyadenosine, with achievable complete remission rates of $80-85 \%$, whereas HCL responds poorly to conventional lymphoma chemotherapy [2]. A precise diagnosis of HCL can be achieved by positive detection of typical neoplastic cells with hairy cytoplasmic projections in the peripheral blood or bone marrow aspirates and characteristic strong expression of B-cell antigens together with CD103, CD11c, CD25 and FMC7 [3-5]. However, unequivocal diagnosis can be difficult in some leukopenic patients with scanty or no neoplastic cells in the peripheral blood $[6,7]$. In addition, HCL-induced bone marrow fibrosis $[8,9]$ can hamper the collection of neoplastic cells by bone marrow aspiration. In such situations, examination of bone marrow trephine histology together with immunohistochemical analysis is the only available method to make a definitive diagnosis of HCL.

\section{KARGER}

Fax +41613061234

E-Mail karger@karger.ch

www.karger.com
(C) 2008 S. Karger AG, Basel

$1015-2008 / 08 / 0754-0252 \$ 24.50 / 0$

Accessible online at:

www.karger.com/pat
Korinna Jöhrens

Institute of Pathology, Charité, Campus Benjamin Franklin

Hindenburgdamm 30

DE-12200 Berlin (Germany)

Tel. +49 308445 2548, Fax +49 308445 4473, E-Mail korinna.joehrens@charite.de 
The currently available monoclonal antibodies (moAbs) to the characteristic antigens expressed by HCL, particularly CD11c and CD103, do not detect formalinresistant epitopes, and therefore, are unsuitable for the assessment of formalin-fixed, decalcified bone marrow trephines. The search for other HCL-characteristic formalin-resistant antigens led to the antibody DBA.44, originally raised against B lymphocytes [10], which was shown to be a marker for HCL [11], and to an moAb against tartrate-resistant acid phosphatase. Although both antibodies can positively label HCL, they lack specificity since they also react in most of the other nonHodgkin lymphoma subtypes [12-14]. However, when DBA.44 and anti-tartrate-resistant acid phosphatase are used in combination, they are useful to diagnose HCL [15]. They are of little value to quantify infiltrates, especially for the evaluation of minimal disease, as a significant proportion of tumor cells are either negative or express these molecules at very low levels [16]. Recently, annexin A1 has been reported to be a highly HCL-specific molecule [17] which can be detected in routinely fixed and decalcified bone marrow biopsies. However, annexin A1 has 2 drawbacks. Firstly, it is also expressed by myeloid cells, which makes identification of low-level disease difficult or impossible, and, secondly, it is not expressed by all HCL cases (personal observations). In the present study, we demonstrate the validity of a newly developed moAb of the CD11c cluster, 5D11, which is effective in formalin-fixed and decalcified material. We show its sensitivity and specificity for HCL and its utility for both diagnosis and monitoring minimal HCL infiltrates in bone marrow biopsies following therapy.

\section{Material and Methods}

Formalin-fixed, paraffin embedded (FFPE) EDTA-decalcified bone marrow trephines of 5 individuals without any pathologic findings and $60 \mathrm{HCL}$ cases with extensive HCL infiltrates were first assessed to investigate the reactivity of the CD11c moAb clone 5D11 (a gift from Vision Biosystems, Novocastra, Newcastle upon Tyne, UK). In addition, splenectomy specimens from 13 patients with extensive HCL involvement were also investigated. The initial diagnosis of the HCL cases had been made on peripheral blood or bone marrow aspirate morphology together with immunophenotyping by flow cy tometry; the hairy cells in all cases expressed CD11c, CD103, CD25 and FMC7 antigens, as well as panB-cell antigens. Once 5D11 had been demonstrated to successfully detect hairy cells in FFPE with and without decalcification, we assessed the specificity of the antibody. We performed immunohistochemical analysis of bone marrow trephines of 42 patients with chronic lymphocytic leukemia (CLL), 8 patients with splenic marginal zone lymphoma (SMZL), 7 patients with mantle cell lymphoma, 12 patients with bone marrow manifestations of nodal and extranodal MZLs and 23 patients with bone marrow infiltration with lymphoplasmacytic lymphoma with antibody 5D11. Finally, we tested the applicability of the CD11c antibody 5D11 in the context of minimal HCL infiltrates in bone marrow trephines; these ranged from 2 to $5 \%$ of total marrow cellularity. These patients had morphologically suspicious B lymphocytes in the peripheral blood ( $\mathrm{n}=21$ cases) or were being monitored after therapy for possible recurrence or disease persistence ( $\mathrm{n}=10$ cases).

Antibody 5D11 is directed against a formalin-resistant epitope of the CD11c antigen and is not effective in flow cytometry or in immunocytochemical analysis of air-dried peripheral blood or bone marrow smears. Prior to incubation with the antibody, the dewaxed FFPE sections were immersed in a citrate buffer (10 mmol, $\mathrm{pH}$ 6.0) and subjected to brief, high temperature heating in a pressure cooker. Bound antibodies were visualized with either an alkaline phosphatase anti-alkaline phosphatase method and FastRed chromogen, or an avidin-biotin immunoperoxidase protocol with diaminobenzidine as the chromogen. All reagents were purchased from Dako, Glostrup, Denmark. All sections were counterstained in hematoxylin and viewed by light microscopy.

\section{Results}

In normal bone marrow, stromal macrophages were the only CD11c-positive cells (fig. 1a). No lymphoid cells were positive, and there was no expression by normal granulocytic cells. The initial assessment of FFPE EDTAdecalcified bone marrow trephines $(n=60)$ and splenectomy $(n=13)$ specimens with extensive HCL infiltrates showed strong unequivocal CD11c-positive labeling of the tumor cell population in all $73 \mathrm{HCL}$ cases analyzed (fig. 1b). The positive staining highlighted the morphological appearance of the cytoplasm, thereby demonstrating the 'hairy' nature of the cell membrane and eccentrically located nucleus. The number of CD11c-positive hairy cells identified in these samples generally appeared to be greater than that anticipated from the hematoxylin and eosin-stained sections.

In the second phase of the study, 92 small B-cell nonHodgkin lymphoma cases were assessed for their reactivity with the CD11c antibody. All cases of CLL, SMZL, mantle cell lymphoma and lymphoplasmacytic lymphoma were CD11c negative (fig. 1d; table 1), except for 1 case of non-splenic MZL lymphoma with marrow infiltration.

Antibody 5D11 was also evaluated for its suitability for the detection of minimal HCL infiltrates (ranging from 2 to $5 \%$ of total marrow cellularity) in bone marrow trephines. In all 31 cases evaluated, distinct positive labeling highlighted any hairy cells present (fig. 1c). The number 
Fig. 1. CD11c labeling of bone marrow trephines. a A normal bone marrow trephine showing CD11c positivity of interstitial macrophages. b Strong CD11c expression in a bone marrow trephine with extensive infiltration by HCL. c A bone marrow with minimal HCL infiltration stained positively with CD11c. d A bone marrow involved with small B-cell lymphoma. CD11c only labels the macrophages, and there is no staining of the tumor population.
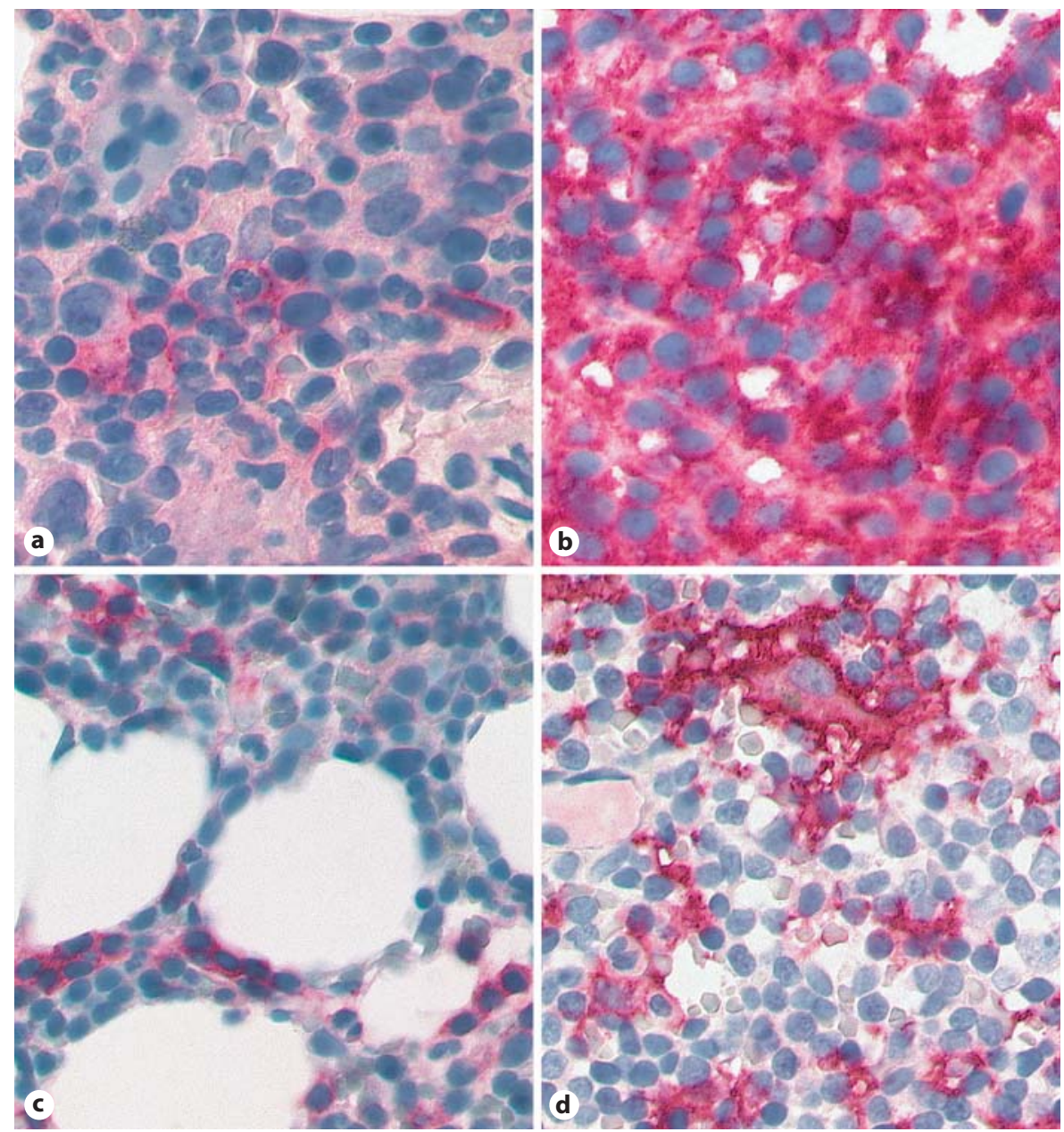

Table 1. Expression patterns of the CD11c antibody effective in formalin-fixed tissue specimens

\begin{tabular}{lc}
\hline Entities & $\begin{array}{l}\text { CD11c } \\
\text { reactivity }\end{array}$ \\
\hline HCL & \\
$\quad$ Extensive infiltration & $73 / 73$ \\
$\quad$ Bone marrow trephines & 60 \\
$\quad$ Spleen & 13 \\
Minimal bone marrow infiltration & $31 / 31$ \\
$\quad$ Suspicious peripheral blood & 21 \\
$\quad$ Post-therapy monitoring & 10 \\
Total & $104 / 104$ \\
CLL $^{1}$ & $0 / 42$ \\
Mantle cell lymphoma $^{1}$ & $0 / 7$ \\
Nodal and extranodal MZL $^{1}$ & $1 / 12$ \\
SMZL $^{1}$ & $0 / 8$ \\
Lymphoplasmacytic lymphoma $^{1}$ & $0 / 23$ \\
\hline
\end{tabular}

${ }^{1}$ Investigation of decalcified bone marrow trephines. of positive cells was variable and they were generally present in small clusters. The hairy cells tended to show stronger CD11c staining than the normal marrow macrophages.

\section{Discussion}

CD11c is an adhesion receptor of the leukocyte function-associated family of molecules [18] and has an established role as a useful molecule for the diagnosis of HCL. This cell surface antigen is normally expressed on granulocytes, monocytes, natural killer cells and small populations of $\mathrm{T}$ and $\mathrm{B}$ lymphocytes. Among malignant lymphomas, CD11c is consistently expressed in HCL and rarely in B-CLL/small lymphocytic lymphoma and splenic MZL [19]. In particular, flow cytometric analysis has revealed that the intensity of CD11c expression in HCL is 30 -fold greater than in B-CLL/SLL and SMZL, thus un- 
derlining its diagnostic utility [20]. This constant high CD11c expression in HCL supports the concept that hairy cells represent highly activated B cells. This activation status is documented not only by the reorganized hairy cell cytoskeleton with the distinctive membrane ruffling and microvillus formation with polymerized F-actin, but also by the strong expression of cell surface structures associated with the activation of normal $\mathrm{B}$ cells (including CD22, CD25, CD72 and CD40 ligand) [21]. The CD11c expression in HCL has been found to be dependent upon activation of the proto-oncogenes ras and junD [22].

Although the diagnostic utility of CD11c expression in fresh unfixed cells has been well established for many years [23], it has remained inaccessible to the surgical pathologist equipped only with formalin-fixed, paraffinembedded tissue specimens. The reason for this has been that the epitopes recognized by the available CD11c clones become degraded or masked following formalin fixation. The new CD11c moAb 5D11, which detects a formalinresistant epitope, will now provide a significant change to the way HCL can be diagnosed and assessed in FFPE. In the present study, we have tested and validated the potential of this CD11c antibody for use in formalin-fixed tissues. All 104 cases of HCL tested, in formalin-fixed or formalin-fixed and decalcified tissue, gave strong specific labeling of the hairy cell tumor population. We also demonstrated that other small B-cell lymphomas, which can be difficult to differentiate from HCL using conventional histology, were, apart from 1 case, CD11c negative. However, the 1 positive case, a non-splenic MZL, could be distinguished from HCL by other criteria: the primary tumor in the lung showed plasmacytoid differentiation and had monotypic expression of the immunoglobulin light chain $\kappa$. Therefore, this analysis confirms that the CD11c antibody is virtually specific for differentiating
HCL from other small B-cell lymphomas. However, it should be noted that these results do not entirely correlate with those obtained by flow cytometry where CD11c can be detected in a larger number of small B-cell lymphomas. This difference is explained by the fact that the CD11c antibody used for the present study is directed against a formalin-resistant epitope and is not effective in unfixed cells.

In this study, we have also demonstrated that the CD11c antibody is able to detect minimal marrow infiltration by HCL. By investigating 31 bone marrow trephines with low-level HCL infiltrates, we could demonstrate the ability of the CD11c antibody to detect HCL to a level of $2 \%$. This implies that immunohistochemical staining of formalin-fixed decalcified bone marrow trephines with CD11c could be used both for early diagnosis of HCL and for detection of residual disease following therapy. It is important to note that the CD11c-positive interstitial macrophages, which were generally more weakly stained than the hairy cells, did not interfere with the identification of the more strongly stained tumor cells.

In summary, we describe a new CD11c antibody which is both specific and sensitive for HCL. Therefore, we propose including it in a diagnostic antibody panel for the evaluation and differential diagnosis of small B-cell lymphoproliferative disorders. The antibody can be applied to formalin-fixed, paraffin-embedded tissue with and without decalcification. Thus, the antibody can be applied to bone marrow trephine biopsies both in the diagnostic setting and monitoring HCL following therapy, as it is able to identify even minimal marrow infiltrates. Importantly, the tumor cells of the majority of other types of small B-cell lymphoma do not express this CD11c antigen.

\section{References}

1 Goodman GR, Bethel KJ, Saven A: Hairy cell leukemia: an update. Curr Opin Hematol 2003;10:258-266.

2 Tallman MS: Current treatment strategies for patients with hairy cell leukemia. Rev Clin Exp Hematol 2002;6:389-400.

3 Westbrook CA, Golde DW: Clinical problems in hairy cell leukemia: diagnosis and management. Semin Oncol 1984;11:514522.
4 Matutes E, Morilla R, Owusu-Ankomah K, Houliham A, Meeus P, Catowsky D: The immunophenotype of hairy cell leukemia (HCL). Proposal for a scoring system to distinguish HCL from B-cell disorders with hairy or villous lymphocytes. Leuk Lymphoma 1994;14(suppl 1):57-61.

-5 Cornfield DB, Mitchell Nelson DM, Rimsza LM, Moller-Patti D, Braylan RC: The diagnosis of hairy cell leukemia can be established by flow cytometric analysis of peripheral blood, even in patients with low levels of circulating malignant cells. Am J Hematol 2001;67:223-226.
6 Bethel KJ, Sharpe RW: Pathology of hairycell leukaemia. Best Pract Res Clin Haematol 2003;16:15-31.

-7 Frassoldati A, Lamparelli T, Federico M, Annino L, Capnist G, Pagnucco G, Dini E, Resegotti L, Damesio EE, Silingardi V: Hairy cell leukemia: a clinical review based on 725 cases of the Italian Cooperative Group (ICGHCL). Italian Cooperative Group for Hairy Cell Leukemia. Leuk Lymphoma 1994;13:307-316. 
$>8$ Aziz KA, Till KJ, Zuzel M, Cawley JC: Involvement of CD44-hyaluronan interaction in malignant cell homing and fibronectin synthesis in hairy cell leukemia. Blood 2000; 96:3161-3167.

$>9$ Burthem J, Cawley JC: The bone marrow fibrosis of hairy-cell leukemia is caused by the synthesis and assembly of a fibronectin matrix by the hairy cells. Blood 1994;83:497504.

10 al Saati T, Caspar S, Brousset P, Chittal S Caveriviere $\mathrm{P}$, Hounieu $\mathrm{H}$, Dastugue N, Idoipe JB, Icart J, Mazerolles C, Delsol G Production of anti-B monoclonal antibodies (DBB.42, DBA.44, DNA.7, and DND.53) reactive on paraffin-embedded tissues with a new B-lymphoma cell line grafted into athymic nude mice. Blood 1989;74:2476-2485.

11 Hounieu H, Chittal SM, al Saati T, de Mascarel A, Sabattini E, Pileri S, Falini B, Ralfkiaer E, Le Tourneau A, Selves J, et al: Hairy cell leukemia. Diagnosis of bone marrow involvement in paraffin-embedded sections with monoclonal antibody DBA.44. Am J Clin Pathol 1992;98:26-33.
12 Hoyer JD, Li CY, Yam LT, Hanson CA, Kurtin PJ: Immunohistochemical demonstration of acid phosphatase isoenzyme 5 (tartrate-resistant) in paraffin sections of hairy cell leukemia and other hematologic disorders. Am J Clin Pathol 1997;108:308-315.

13 Janckila AJ, Cardwell EM, Yam LT, Li CY: Hairy cell identification by immunohistochemistry of tartrate-resistant acid phosphatase. Blood 1995;85:2839-2844.

14 Yam LT, Janckila AJ, Li CY, et al: Cytochemistry of tartrate-resistant acid phosphatase: 15 years' experience. Leukemia 1987;1:285288.

15 Went PT, Zimpfer A, Pehrs AC, Sabattini E, Pileri SA, Maurer R, Terracciano L, Tzankov A, Sauter G, Dirnhofer S: High specificity of combined TRAP and DBA.44 expression for hairy cell leukemia. Am J Surg Pathol 2005; 29:474-478.

16 Bethel KJ, Sharpe RW: Pathology of hairycell leukaemia. Best Pract Res Clin Haematol 2003;16:15-31.

17 Falini B, Tiacci E, Liso A, Basso K, Sabattini E, Pacini R, Foa R, Pulsoni A, Dalla Favera R, Pileri S: Simple diagnostic assay for hairy cell leukaemia by immunocytochemical detection of annexin A1 (ANXA1). Lancet 2004;363:1869-1870.
8 Arnaout MA: Structure and function of the leukocyte adhesion molecules CD11/CD18. Blood 1990;75:1037-1050.

19 Marotta G, Raspadori D, Sestigiani C, Scalia G, Bigazzi C, Lauria F: Expression of the CD11c antigen in B-cell chronic lymphoproliferative disorders. Leuk Lymphoma 2000; 37:145-149.

20 Robbins BA, Ellison DJ, Spinosa JC, Carey CA, Lukes RJ, Poppema S, Saven A, Piro LD: Diagnostic application of two-color flow cytometry in 161 cases of hairy cell leukemia. Blood 1993;82:1277-1287.

21 Zuzel M, Cawley JC: The biology of hairy cells. Best Pract Res Clin Haematol 2003;16: $1-13$

22 Nicolaou F, Teodoridis JM, Park H, Georgakis A, Farokhzad OC, Böttinger EP, Da Silva N, Rousselot P, Chomienne C, Ferenczi K, Arnaout MA, Shelley CS: CD11c gene expression in hairy cell leukemia is dependent upon activation of the proto-oncogenes ras and junD. Blood 2003;101:4033-4041.

23 Schwarting R, Stein H, Wang CY: The monoclonal antibodies alpha S-HCL 1 (alpha Leu14) and alpha S-HCL 3 (alpha Leu-M5) allow the diagnosis of hairy cell leukemia. Blood 1985;65:974-983. 